\title{
Ranking sires using genetic selection indices based on financial investment methods versus lifetime net merit
}

\author{
Michael R. Schmitt, ${ }^{1}$ Paul M. VanRaden, ${ }^{2}$ and Albert De Vries ${ }^{1 *}$ \\ ${ }^{1}$ Department of Animal Sciences, University of Florida, Gainesville 32611 \\ ${ }^{2}$ Animal Genomics and Improvement Laboratory, Agricultural Research Service, USDA, Beltsville, MD 20705
}

\section{ABSTRACT}

Current USDA selection indices such as lifetime net merit $(\mathrm{NM} \$)$ estimate lifetime profit differences, which are accurately approximated by a linear combination of 13 traits. In these indices, every animal gets credit for 2.78 lactations of the traits expressed per lactation, such as fat and protein, independent of its productive life (PL). This formulation may over- or underestimate the net revenue from traits expressed per lactation depending on PL. The objectives were to develop 2 genetic selection indices using financial investment methods to account for differences in PL and to compare them with the $2017 \mathrm{NM} \$$ for marketed Holstein sires. Selection among animals with different PL is an example of investment in mutually exclusive projects that have unequal duration. Financial investment theory says that such projects are best compared with the annualized net present value (ANPV) method when replacement occurs with technologically equal assets. However, genetic progress implies that future available replacement animals are technologically improved assets. Asset replacement theory with improved assets results in an annualized value including genetic opportunity cost (AVOC) for each animal. We developed the ANPV and AVOC and compared these with the NM\$ for 1,500 marketed Holstein sires from the December 2017 genetic evaluation. The lowest Pearson correlation coefficient was 0.980 between AVOC and NM\$, whereas the highest was 0.999 between ANPV and NM\$ among the 1,500 sires. Correlations for the top 300 sires were lower. Although we found high correlations between indices, the 95 th and 5 th percentiles of individual rank changes between AVOC and NM $\$$ were +131 and -163 positions, respectively, whereas these changes between ANPV and NM $\$$ were +27 and -45 positions, respectively. The relative emphasis of PL in the AVOC index was half of the relative emphasis in $\mathrm{NM} \$$. These results

Received November 30, 2018.

Accepted May 29, 2019.

*Corresponding author: devries@ufl.edu show that applying financial investment methods to value differences in genetic merit of animals changes their rankings compared with the $\mathrm{NM} \$$ formulation. Rank changes were meaningful enough that the new indices warrant consideration for use in practice.

Key words: lifetime profit, genetic merit, selection index, financial analysis

\section{INTRODUCTION}

Dairy cattle breeders rely on genetic selection indices to achieve their breeding objectives. In the United States, a well-known selection index based on economically important traits is the lifetime net merit (NM\$) developed by the USDA (VanRaden, 2000, 2017). The breeding objective of $\mathrm{NM} \$$ is to maximize profitability during the lifetime of the offspring of the animal (Cole and VanRaden, 2018). The official $2017 \mathrm{NM} \$$ is a linear approximation of a nonlinear combination of PTA for 13 traits and their marginal economic weights, equal to their net revenue for a single unit change in PTA.

In this study, we focus on the traits that are transmitted from sires to their daughters. In the $2017 \mathrm{NM} \$$, every sire gets credit for 2.78 lactations for the 10 traits that have repeated net revenues in every lactation, such as milk, fat, protein, and daughter pregnancy rate (DPR). Only the traits heifer conception rate (HCR), productive life (PL), and livability (LIV) occur once in a lifetime. The trait PL is used to predict the number of additional lactating months over the breed base and, by extension, the milking lifetime of the animal. Because PTA of PL vary between animals, animals with a negative PTA of PL are expected to remain in the herd for shorter than 2.78 lactations (27.8 lactating months), whereas animals with a positive PTA of PL are expected to remain longer in the herd. These differences in PL are not included in the net revenue that is calculated from the traits that repeat every lactation because the standard 2.78 lactations is used for every animal, independent of its PTA for PL.

Genomic selection has accelerated genetic progress per unit of time (García-Ruiz et al., 2016; CDCB, 2018). 
This implies that there is an opportunity cost by keeping an animal in the herd when a potential replacement is genetically superior (De Vries, 2017). Especially animals with positive PTA for PL but low values for traits that repeat every lactation incur a large opportunity cost. These animals are expected to stay in the herd longer but are less profitable on a daily basis. The need to include opportunity cost of postponed replacement has been demonstrated in profit functions when comparing incomes from production and extending herd life (Van Arendonk, 1991; Weigel et al., 1995; Cassell et al., 2002; Groenendaal et al., 2004). Opportunity cost of postponed replacement is not included in the 2017 $\mathrm{NM} \$$.

Considering the fixed 2.78 lactations for traits that repeat every lactation and lack of inclusion of genetic opportunity cost, it is likely that $\mathrm{NM} \$$ and equivalent indices may not fully capture the financial differences of genetic expression when selection is viewed as a financial investment. The components of the $\mathrm{NM} \$(\mathrm{PTA}$ and economic weights) can be used in financial methods for valuing investment returns with different lifetimes. Differences between investment lifetimes (e.g., differences in PL) can be adjusted to an equal planning horizon through the standard financial investment analysis method of annualized net present value (ANPV; Brown and Davis, 1998). With the ANPV method, investment alternatives with unequal lifetimes can be compared. Applied to genetic selection, net revenue generated from traits expressed during the predicted number of lactations - both the traits that repeat every lactation and those that occur only once - can be expressed in an ANPV. The simplest form of ANPV assumes replacement with an equal asset, but the approach can be modified to an annualized value including genetic opportunity cost (AVOC). To our knowledge, these financial investment methods have not yet been used in animal breeding to calculate economic genetic selection indices.

Selection indices based on financial investment methods could change the rankings of animals based on their genetic merit compared with their ranking based on the lifetime NM\$ formula. Therefore, the objective of this study was to develop 2 genetic selection indices using financial investment methods, one with genetic opportunity cost and one without, and to compare them with the 2017 NM\$ for marketed Holstein sires.

\section{MATERIALS AND METHODS}

The data included official PTA values and official $\mathrm{NM} \$$ from the December 2017 genetic evaluation of the highest 1,500 marketed Holstein sires for NM\$. We obtained data from the Council on Dairy Cattle Breeding public database (CDCB, 2017). We chose only Holstein sires because of the large data set available compared with other breeds. Sires were required to have semen publicly available for purchase because most dairy farmers would make sire selections from within this group. Data were stored and analyzed in Microsoft Excel (Microsoft Corp., Redmond, WA).

The $2017 \mathrm{NM} \$$ contains the traits milk, fat, protein, DPR, HCR, PL, LIV, SCS, cow conception rate (CCR), udder composite (UDC), feet and legs composite (FLC), BW composite (BWC), and calving ability (CA\$). Summary statistics for the top 1,500 Holstein sires and the top 300 of these sires ranked by $\mathrm{NM} \$$ are presented in Table 1.

Table 1. Minimum, average, and maximum values for PTA of the traits in the lifetime net merit dollars index (NM $\$$ ) of the top 300 and 1,500 marketed Holstein sires for NM\$ in the December 2017 genetic evaluation

\begin{tabular}{|c|c|c|c|c|c|c|c|c|}
\hline Trait $^{1}$ & Unit & $\begin{array}{c}\text { Economic weight, } \\
\$ / \text { lactation }\end{array}$ & \multicolumn{3}{|c|}{ Top 300 sires } & \multicolumn{3}{|c|}{ Top 1,500 sires } \\
\hline PRO & Pounds & 1.37 & 26 & 59 & 90 & 18 & 52 & 90 \\
\hline $\mathrm{PL}$ & Months & Lifetime $^{2}$ & 5.2 & 8.6 & 12.7 & 1.9 & 7.4 & 12.7 \\
\hline LIV & Percentage & Lifetime & -1.6 & 2.4 & 6.4 & -3.3 & 1.6 & 6.9 \\
\hline HCR & Percentage & Lifetime & -0.2 & 2.5 & 5.8 & -3.2 & 2.2 & 5.8 \\
\hline CCR & Percentage & 0.91 & 0.5 & 4.5 & 8.3 & -1.5 & 3.7 & 10 \\
\hline UDC & Composite & 11.15 & 0.6 & 1.94 & 3.33 & -0.54 & 1.88 & 4.00 \\
\hline FLC & Composite & 3.60 & -0.48 & 1.20 & 2.66 & -0.98 & 1.18 & 3.02 \\
\hline BWC & Composite & -7.19 & -2.05 & -0.04 & 2.06 & -2.16 & 0.26 & 2.47 \\
\hline $\mathrm{CA} \$$ & Dollars & 0.36 & 4.3 & 46.9 & 76.5 & -14.8 & 41.4 & 86.2 \\
\hline $\mathrm{NM} \$$ & Dollars & Lifetime & 871 & 920 & 1,116 & 665 & 794 & 1,116 \\
\hline
\end{tabular}

${ }^{1} \mathrm{PRO}=$ protein $; \mathrm{PL}=$ productive life LIV = livability; $\mathrm{DPR}=$ daughter pregnancy rate $\mathrm{HCR}=$ heifer conception rate; $\mathrm{CCR}=$ cow conception rate; $\mathrm{UDC}=$ udder composite; FLC $=$ feet and legs composite; $\mathrm{BWC}=\mathrm{BW}$ composite; $\mathrm{CA} \$=$ calving ability.

${ }^{2}$ Lifetime weight used in the NM\$ 2017 index and not converted to lactation basis. 


\section{ANPV}

The net present value (NPV) is the net profit generated in today's dollars given the discount rate over the investment's lifetime and, if positive, is preferred to an alternative investment valued at the discount rate (Higgins, 2001). When multiple mutually exclusive investments with different lifetimes are under consideration, where acceptance of one leads to rejection of the others as is the case with selecting a sire for mating, a method for comparing the NPV over a common planning horizon is preferred (Higgins, 2001). In this method, the NPV is multiplied by the present value interest factor for annuity (PVIFA) at the expected lifetime of the investment to evenly compare investments over a common annual planning horizon (Brown and Davis, 1998). The ANPV of a sire through his daughters is calculated by the following equation using the traits in the 2017 $\mathrm{NM} \$$ :

$\mathrm{ANPV}=\left\{\right.$ entry $\left.+\left[\sum_{i=1}^{n} \frac{\left(\sum_{j=1}^{10} \text { lact }_{j}\right)+\text { base }}{(1+r)^{t_{i}}}\right]+\frac{\text { exit }}{(1+r)^{n}}\right\} \times \frac{r}{1-(1+r)^{-n}}$,

where $r=$ annual discount rate; entry $=$ cost of the heifer entering the milking herd plus net revenue of HCR; lact $_{j}=$ net revenue from trait $j$ that repeats every lactation in lactation $i$; base $=$ breed base net revenue constant; $t_{i}=5$ mo into lactation $i$ for completed lactations or halfway through the last, incomplete lactation; exit $=$ exit value and net revenue of LIV; and $n=$ number of lactations, including a fraction of the last lactation. In this formula, $r /\left[1-(1+r)^{-n}\right]=$ PVIFA and $\mathrm{ANPV}=\mathrm{NPV} \times \mathrm{PVIFA}$. A completed lactation is 10 mo of milk production and 2 mo dry, so 1 lactation equals $1 \mathrm{yr}$. The time origin for discounting was set to the start of the first lactation.

To calculate the ANPV for each sire, the annual discount rate $(r)$ was set at $5 \%$. All other marginal economic values were set the same as in the 2017 NM\$ (VanRaden, 2017). The cost of a heifer entering the milking herd was set at $\$ 1,480$. This is the cost of a heifer at first calving, which includes the calf value, the cost of rearing, and reproductive costs (VanRaden, 2017). The net revenue of PTA of HCR was added to the heifer entry cost. It is expressed only once, and the net revenue from HCR is assumed to be realized at the start of the first lactation. The marginal economic value of HCR is $\$ 2.26 /$ percentage point. Therefore, the entry value at first calving was calculated as $-\$ 1,480+$ PTA of HCR $\times \$ 2.26$.

The LIV trait is expressed only at the end of the last lactation and combined with the salvage value is equal to the exit value. The net revenue from differ- ences in PTA of LIV was multiplied by their economic weight ( $\$ 12 /$ percentage point). The salvage value was calculated as the difference between the entry value and the total depreciation over the animal's lifetime as calculated by the marginal economic value of $\mathrm{PL}$ $(\$ 21 / \mathrm{mo})$, as the monthly change in depreciation, over the standard lifetime of 2.78 lactations $(2.78 \times 10 \mathrm{mo} /$ lactation $\times \$ 21=\$ 584)$. Thus $\$ 1,480$ (entry value) $\$ 584$ (depreciated value) $=\$ 896$ salvage value. The exit value did not depend on the individual sire's PTA for PL. Therefore, the exit value was calculated as $\$ 896+$ PTA of LIV $\times \$ 12$.

Ten traits generated net revenue in each lactation. Economic weights from NM\$ (Table 1) were divided by 2.78 to obtain marginal economic values per lactation. These traits with their marginal economic values per lactation are milk $(\$ 0.0014 / \mathrm{lb}$.$) , fat (\$ 1.28 / \mathrm{lb}$.), protein $(\$ 1.37 / \mathrm{lb}$.$) , SCS (-\$ 42.09 / \log )$, DPR (\$3.96/ percentage point), CCR (\$0.91/percentage point), UDC (\$11.15/composite unit), FLC (\$3.60/composite unit), BWC ( $-\$ 7.19 /$ composite unit), and CA $\$$ $(\$ 0.36 / \$ 1.00)$. Lactation weights were multiplied by their respective PTA and then summed to obtain the net revenue per lactation for each trait. The total net revenue per lactation was multiplied by the expected number of lactations $(n)$, which depends on PTA for PL, to obtain the total net revenue from the lactation traits. Lactation net revenue was discounted to account for the time since entry when traits are expressed on average.

The PTA are differences in genetic merit from the base animal, a cow born in 2010. The net revenue of the lactation traits from this base animal is not likely $\$ 0$, however. Because the entry value is greater than the salvage value, the ANPV calculation with PTA all set to 0 would yield a large negative value. To obtain an ANPV that is a realistic estimate of profitability, we added a breed base net revenue to each lactation. This breed base revenue was found by obtaining the value required to be generated from each lactation to equal an overall investment NPV of $\$ 0$ when all PTA equal 0 will overcome the value lost $(-\$ 584)$ between the cost of new heifer replacement and salvage income. The breed base revenue was therefore set at $\$ 343.52$ per lactation.

The number of lactations for each sire depends on his PTA for PL. Genetically, cows have the ability to survive longer in the herd than previous generations given the increase in PTA for PL over time (CDCB, 2018). The average PTA for PL in our data set was +7.4 mo. However, we did not expect that the daughters of these sires on average stay 7.4 mo longer in the herd, thereby reducing the phenotypic annual cow cull rate. National cow cull rates have been consistent in the past decades 
at approximately $35 \%$ despite genetic progress in $\mathrm{PL}$ (De Vries, 2017; CDCB, 2018). This is the result of competition within the herd and dairy farmers' desire to replace cows with heifers with greater genetic merit (De Vries, 2017). Therefore, an adjustment of the effect of PL on the expected number of lactations was necessary to reconcile greater PL with a constant annual cow cull rate. The average PTA of PL of all 1,500 sires $(+7.4 \mathrm{mo})$ was subtracted from each sire's PTA of PL to create an adjusted additional number of lactations for each sire. Because 10 lactating mo is equivalent to 1 lactation, we divided the adjusted additional number of lactations by 10 and added this value to the standard 2.78 lactations. Therefore, the adjusted additional number of lactations was negative for sires with a PTA of PL $<7.4$ mo. The average number of expected lactations therefore remained at 2.78, and thus no change in annual cow cull rate was expected.

\section{Annualized Value with Opportunity Cost}

The ANPV method assumes that the initial asset is replaced with a new asset equal to the asset of the initial investment. This means that a sire would be replaced by an identical sire at the end of his daughters' expected number of lactations. Our second economic selection index therefore includes a genetic opportunity cost of delaying replacement with genetically superior sires instead of identical sires. A sire's AVOC is calculated using the following equation:

$$
\mathrm{AVOC}=\left\{\mathrm{NPV}+(T-n) \times\left[\frac{\operatorname{start}+\text { trend } \times t_{p}}{(1+r)^{t_{p}}}\right]\right\} / T,
$$

where NPV $=$ the net present value of the sire as explained above; $T=$ planning horizon set to 3.307 lactations (explained below); $n=$ expected number of lactations based on the sire's PTA of PL; start $=$ the starting value of the genetic trend at $t=0$ set at $\$ 342$ (explained below); trend $=$ the annual genetic increase in net revenue from genetic progress set at $\$ 27.99$ (explained below); $t_{p}=$ mean of expected number of lactations and planning horizon, calculated as $t_{p}=(n+$ $T) / 2$; and $r=$ annual discount rate. The summed NPV from the initial sire and replacement sires was divided by the planning horizon to annualize the investment return.

In this formula, the discounted net revenue of genetically improved replacement sires was added to the NPV of the initial sire to complete the planning horizon since the first entry of the initial sire. Of the 1,500 sires, the maximum PTA of PL was +12.7 mo, which resulted in a maximum expected number of lactations of 3.307. This is equivalent to 39.68 mo since the start of the first lactation and was used as the planning horizon.

Multiple generations of replacement sires will succeed beyond the first replacement sire, with diminishing differences between each subsequent sire due to discounting, before the entire effect from the length of the initial sire's lifetime is realized (Perrin, 1972). Therefore, we used a replacement sire at the average of the remaining time in the planning horizon as an approximation of the replacement sires' net genetic value. The net revenue from the replacement sires depended on the trend of genetic progress, the starting value of this genetic trend, and the discount factor, as follows.

A constant rate of genetic progress was anticipated to continue throughout the planning horizon based on an assumed increase of $\$ 85.50$ in PTA of NM\$ per year of marketed sires (De Vries, 2017). Because replacement sires' contributions are multiplied by a yearly value, a linear regression equation of NPV per expected number of lactations was fit as the response and $\mathrm{NM} \$$ was the explanatory variable for all 1,500 sires. The $\mathrm{NM} \$$ coefficient was 0.327 , which was multiplied by the expected progress in $\mathrm{NM} \$$ per year to find the trend of genetic progress of $\$ 27.99 / \mathrm{yr}$. We chose the starting value for the genetic trend to be the average net genetic value per year of the top 100 sires ranked for ANPV, which was $\$ 342$. We assumed that a dairy farmer would choose from the average of this group of sires when the initial sire was no longer retained. A $5 \%$ annual discount rate was applied to the replacement sires' net genetic value.

In a visual example, Figure 1 depicts our approach to combine the genetic values of the initial sire and the replacement sires. For example, suppose an initial sire has an NPV of $\$ 800$ realized during 2.5 lactations based on PTA for PL of +4.6 mo $(2.78 \times 10+4.6-$ $7.4=25.0 \mathrm{mo}$; equal to 2.5 lactations; thick horizontal line). The remaining $0.807 \mathrm{yr}$ of the $3.307-\mathrm{yr}$ planning horizon is completed by the replacement sires (thick diagonal line). The midpoint for replacement $(t)$ was $2.9035 \mathrm{yr}$ and corresponds to $(\$ 342+2.9035 \times \$ 27.99) /$ $(1+0.05)^{2.9035}=\$ 367.36$ for the replacement sires' net genetic value per year. The AVOC of this example sire is therefore $(\$ 800+0.807 \times \$ 367.36) / 3.307=\$ 331.56$.

\section{Data Analysis}

Both ANPV and AVOC are expressed in annual dollars, so lifetime $\mathrm{NM} \$$ was converted to an annual equivalent (annualized $\mathrm{NM} \$$; $\mathbf{A N M} \$$ ), calculated as $\mathrm{NM} \$ / 2.78$, to facilitate comparing the index values when needed. Our new indices ANPV and AVOC were compared with NM $\$$ through Pearson correlations, Spearman rank correlations, and rank changes, in addi- 
tion to ANM $\$$ compared with ANPV and AVOC for index changes, of the full data set of 1,500 sires as well as the top 300 sires ranked for NM $\$$. Standard errors of correlations were calculated as $\sqrt{\left(1-\text { correlation }^{2}\right)} / \sqrt{(n-2)}$. Furthermore, the Pearson correlation of each PTA trait to each index was calculated.

A sensitivity analysis tested differences in Pearson correlations between the new indices and $\mathrm{NM} \$$ by changing the annual discount rate and adjusting the starting value of the genetic trend for replacement sires in the AVOC method.

Index changes compared with ANM $\$$ were quantified using the following regression equation:

$$
\text { index value }=\beta_{0}+\beta_{1} \times \mathrm{ANM} \$+\varepsilon,
$$

where the index value was either the ANPV or AVOC and $\beta_{0}$ and $\beta_{1}$ are regression coefficients. The error term $(\varepsilon)$ was considered the change of index value to be used in the equation below. The PTA traits associated with the change of index and change of rank were found by constructing regression equations with the change of index or change of rank as the response and all PTA traits as explanatory variables:

$$
\text { change }=\beta_{0}+\sum_{i=1}^{13} \beta_{i} \times \text { trait }_{i}+\mathrm{PL}^{2}+\varepsilon,
$$

where change was either the change of rank or change of index value, trait was the PTA of the 13 traits in the indices, $\beta_{0}$ and $\beta_{i}$ are regression coefficients, and $\varepsilon$ is the residual.. The trait PL required an additional squared term in the model for rank change and index value change to obtain normally distributed residuals (data not shown).

The relative emphasis of each PTA trait for each index was calculated from the coefficients from the following equation:

$$
\text { index }=\beta_{0}+\sum_{i=1}^{13} \beta_{i} \times \text { trait }_{i}+\varepsilon,
$$

where index was ANM $\$$, ANPV, or AVOC, where $\beta_{0}$ and $\beta_{i}$ are regression coefficients, $i$ is one of 13 traits,

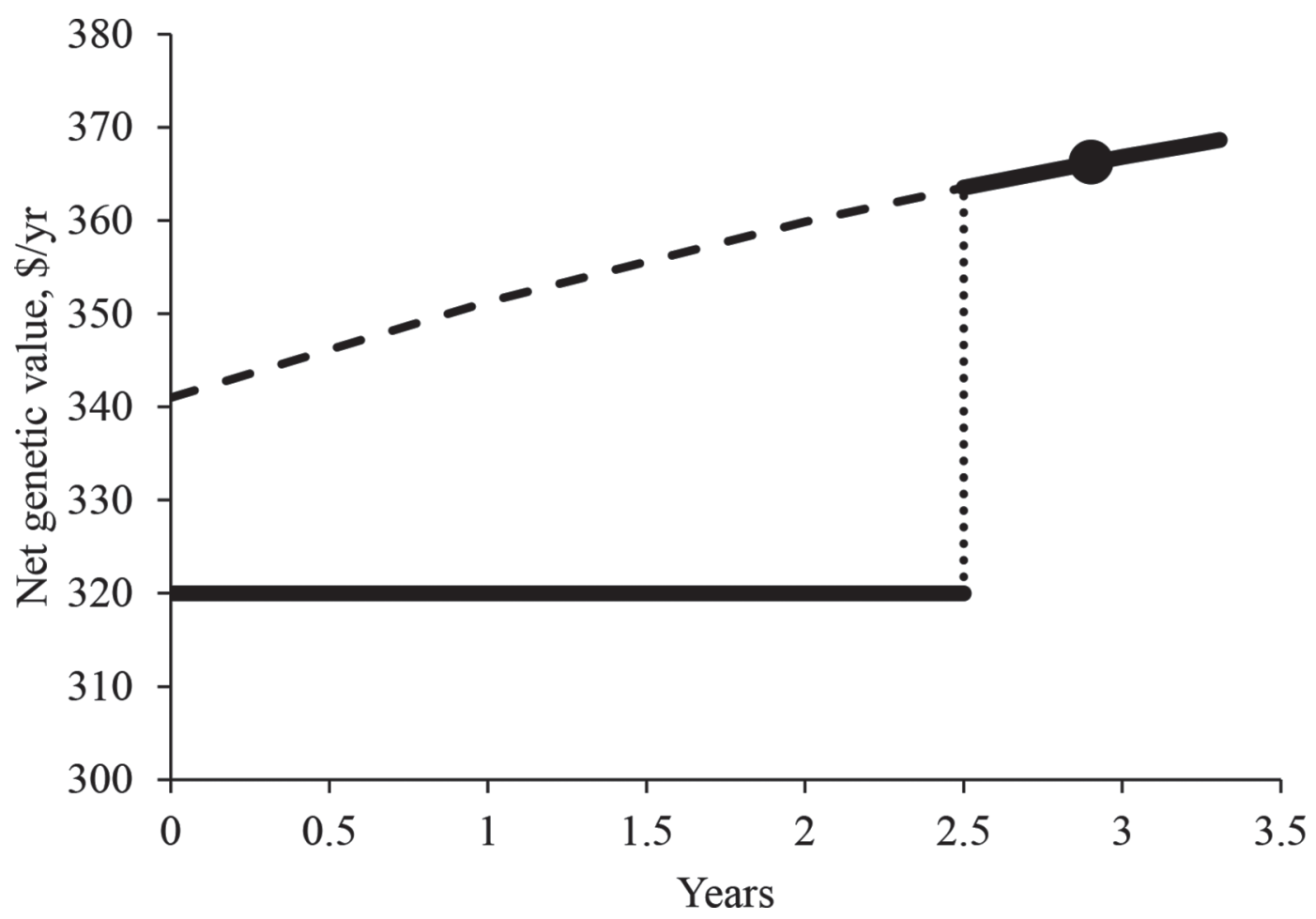

Figure 1. Example of the determination of the annualized value with opportunity cost (AVOC). The initial sire generates a net present value of $\$ 800$ divided by 2.5 expected lactations in the herd to equal $\$ 320 / \mathrm{yr}$ (thick horizontal line). The genetic value of the replacement sires starts at $\$ 342 /$ yr, equal to the average of the top 100 sires for net genetic value per year, and increases at a rate of $\$ 27.99 /$ yr. When the initial sire's daughters are culled, the replacement sires' net genetic value per year equals the average of the replacements at the time of transition and the end of the planning horizon and then discounted at $5 \%$, which in this example equals $\$ 367.36$ (circle). The planning horizon was equal to the longest expected number of lactations in the data set $(3.307 \mathrm{yr})$. The average of each thick line was multiplied by its length and summed before dividing by the length of the planning horizon to equal the AVOC. The AVOC of the example sire is therefore $(\$ 800+0.807 \times \$ 367.36) / 3.307$ $=\$ 331.56$. 
and $\varepsilon$ is the residual. Relative emphasis for each trait in each index was found with the equation

$$
\text { relative emphasis } e_{i}=\left|\beta_{i} \times \mathrm{SD}_{i}\right| / \sum_{j=1}^{13}\left|\beta_{j} \times \mathrm{SD}_{j}\right| \text {, }
$$

where $\mathrm{SD}_{i}$ is the standard deviation of the true transmitting ability for the trait $i$ (VanRaden, 2017), $j$ is one of 13 traits, and $\beta_{i}$ and $\beta_{j}$ are regression coefficients of the 13 traits as defined before.

\section{RESULTS}

\section{Descriptive Statistics}

Table 1 contains the minimum, average, and maximum PTA values of all traits for the data set of 1,500 sires and the highest 300 sires ranked by $\mathrm{NM} \$$. The average PTA of NM $\$$ of all 1,500 sires was $\$ 794$ (minimum $=\$ 665 ;$ maximum $=\$ 1,116)$. The average and minimum $\mathrm{NM} \$$ for the top 300 sires were $\$ 920$ and $\$ 871$, respectively. The average ANM $\$$ of the 1,500 sires was $\$ 286$. The PTA of PL ranged from +1.9 to +12.7 mo, with an average of +7.4 mo. The average PTA for $\mathrm{PL}$ of the top 300 sires was +8.6 mo. For the 1,500 sires, the minimum and maximum for ANPV were $\$ 256$ and $\$ 431$, respectively, and for AVOC were $\$ 255$ and $\$ 389$, respectively. Averages of ANPV and AVOC were $\$ 314$ and $\$ 300$, respectively. Standard deviations were $\$ 30, \$ 31$, and $\$ 22$ for ANM $\$$, ANPV, and AVOC, respectively.

Figure 2 shows the ANPV and AVOC of the highest 300 sires for NM\$. The AVOC consists of the value from the current sire (in gray) and the value from the replacement sires (in black). Only 1 sire ( $\mathrm{NM} \$$ of $\$ 888$ ) does not have any replacement sires' net genetic value because his expected number of lactations equals the planning horizon of $3.307 \mathrm{yr}$. The average difference between both the ANPV (blue line) and AVOC and the ANM \$ (yellow line) and AVOC was \$14. This resulted from our choices made in determining the starting value of the genetic trend for replacements, slope of the genetic trend, length of planning horizon, and the discount rate.

\section{Correlation and Sensitivity Analysis}

We observed high correlations $(\geq 0.978)$ among the 3 indices for the group of 1,500 sires (Table 2). All correlations in the group of 300 sires were lower than

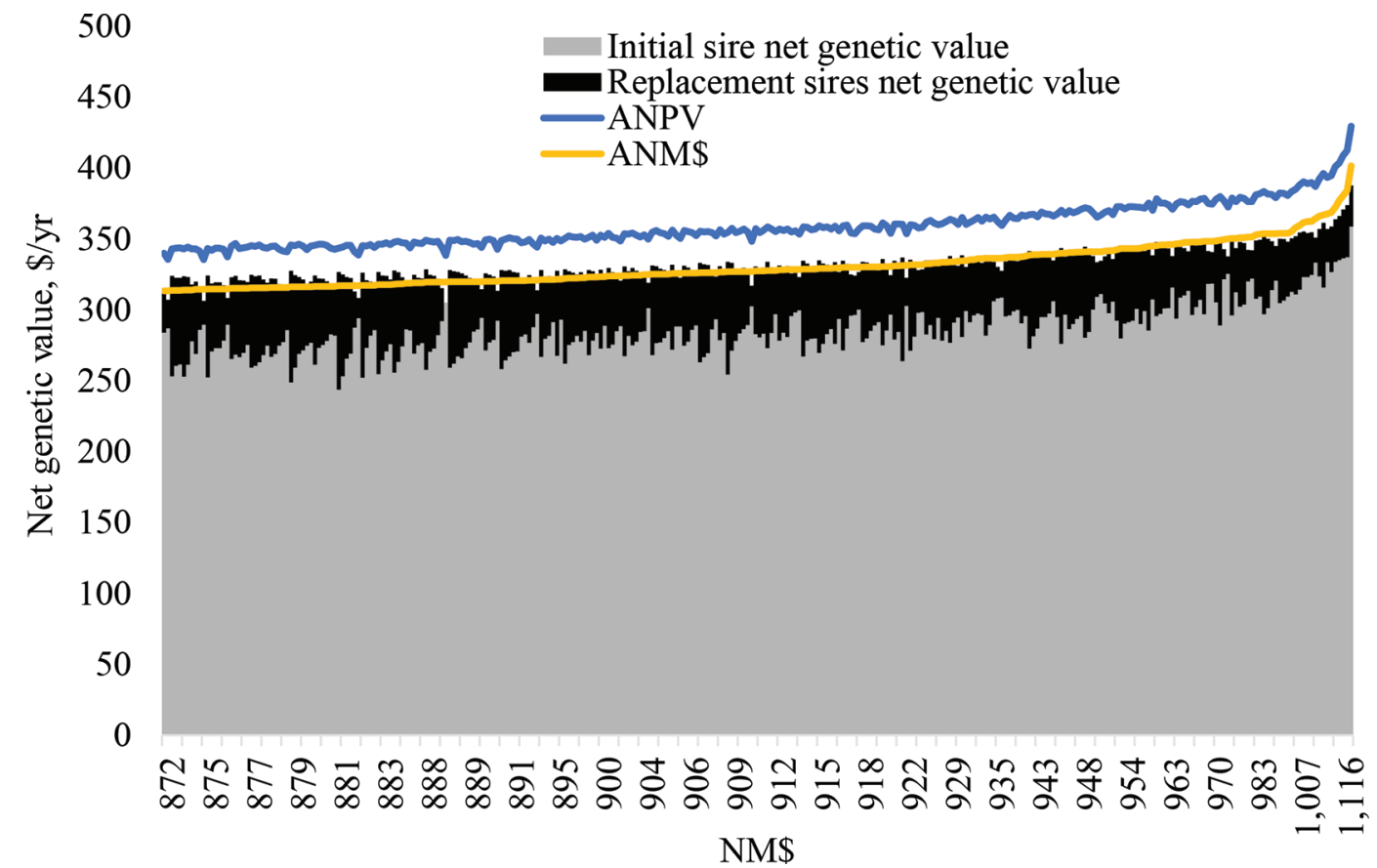

Figure 2. Net present value from the initial sire divided by the sire's expected number of lactations (gray) and replacement sires' net genetic value divided by their expected number of lactations (black), ordered by net merit dollars (NM\$) for the top 300 Holstein sires ranked for NM\$. The sum of both values equals the annualized value with opportunity cost for the planning horizon of 3.307 yr. The blue line represents the annualized net present value (ANPV), and the yellow line represents the annualized $\mathrm{NM} \$(\mathrm{ANM} \$$ ) of the same 300 sires. When $\mathrm{NM} \$$ was equal among sires, the second level of ordering was based on descending PTA for productive life. The sire with an NM $\$$ of $\$ 888$ has a replacement sire's net genetic value of $\$ 0$ because his productive life is the greatest in the group $(+12.7$ mo $)$ and therefore his lifetime was equal to the planning horizon. 
Table 2. Pearson correlations (below the diagonal) and Spearman rank correlations (above the diagonal) for 3 selection indices (SE in parentheses)

\begin{tabular}{llll}
\hline $\begin{array}{l}\text { Selection } \\
\text { index }\end{array}$ & \multicolumn{1}{c}{ NM\$ } & \multicolumn{1}{c}{ ANPV } & \multicolumn{1}{c}{ AVOC } \\
\hline 1,500 Sires & & & \\
NM\$ & 1 & $0.999(0.001)$ & $0.978(0.005)$ \\
ANPV & $0.999(0.001)$ & 1 & $0.981(0.005)$ \\
AVOC & $0.980(0.005)$ & $0.983(0.005)$ & 1 \\
300 Sires & 1 & $0.977(0.012)$ & $0.861(0.029)$ \\
NM\$ & $0.991(0.008)$ & 1 & $0.940(0.020)$ \\
ANPV & $0.945(0.019)$ & $0.977(0.012)$ & 1 \\
AVOC &
\end{tabular}

${ }^{1} \mathrm{NM} \$$ = lifetime net merit dollars; ANPV = annualized net present value; $\mathrm{AVOC}=$ annualized value with opportunity cost.

in the group of 1,500 sires. Spearman rank correlations were generally 0.001 lower than Pearson correlations for the group of 1,500 sires and 0.06 lower for the top 300 sires. The lowest Spearman correlation was 0.861 (AVOC with NM\$ for the top 300 sires). All correlations of $\mathrm{NM} \$$ with AVOC were lower than correlations of $\mathrm{NM} \$$ with ANPV.

The Pearson correlations were used in the sensitivity analysis of AVOC when changing the starting value of the genetic trend and discount rate. The correlation of ANPV and NM\$ with AVOC was 0.983 and 0.980, respectively, when the starting value for the genetic trend of replacement sires was $\$ 342$ for the group of 1,500 sires. When the starting value was set equal to the highest genetic value per year of all sires (\$390), the correlation between ANPV and AVOC reduced to 0.965 and the correlation between NM $\$$ and AVOC reduced to 0.961 . When the average net genetic value per year of all 1,500 sires (\$287) was used, the correlation of ANPV with AVOC increased to 0.995 and the correlation of NM\$ with AVOC increased to 0.993. Thus, lower starting values resulted in higher correlations of ANPV and NM\$ with AVOC. Correlations for the top 300 sires followed the same trends but were lower.

When the annual discount rate for the initial and replacement sires was increased from $5 \%$ to $10 \%$, the correlation of ANPV with NM\$ decreased to 0.998, the correlation of ANPV with AVOC increased to 0.988, and the correlation of $\mathrm{AVOC}$ with $\mathrm{NM} \$$ increased to 0.984 . When the annual discount rate was reduced to $0 \%$, the correlation of ANPV with NM $\$$ remained at 0.999, but the correlation of ANPV with AVOC decreased to 0.974 and the correlation of AVOC with $\mathrm{NM} \$$ decreased to 0.972 .

Pearson correlations of the 3 indices with the individual PTA of the 13 traits are shown in Table 3 for the 1,500 sires. Correlations were in the same direction for each PTA trait across the 3 indices but magnitudes differed. The correlations of the individual traits with
ANPV were very similar to correlations with $\mathrm{NM} \$$ and changed less than 0.03 for all traits. The highest correlations with the 3 indices were for fat $(\geq 0.55)$. The traits milk, fat, protein, and SCS had higher correlations with AVOC compared with $\mathrm{NM} \$$ by $+0.06,+0.12,+0.08$, and +0.09 , respectively. The traits PL, LIV, DPR, HCR, and CCR had lower correlations with AVOC by $-0.18,-0.14,-0.11,-0.05$, and -0.11 relative to correlations with $\mathrm{NM} \$$. Correlations of conformation (UDC, FLC, and BWC) and calving traits $(\mathrm{CA} \$)$ were very similar across the 3 indices. The correlations of PL with NM\$, ANPV, and AVOC were 0.52, 0.50, and 0.34 , respectively. Correlations for the top 300 sires were similar.

\section{Rank Changes}

Rank positions of sires for each index were compared, to investigate the direction and size of rank changes when a different index was used. Positive rank changes represent sires that ranked higher for ANPV or AVOC compared with $\mathrm{NM} \$$. For the 1,500 sires, differences between the NM\$ rank and ANPV rank resulted in a maximum decrease of 164 positions and a maximum increase of 53 positions (Figure 3 ). We observed maximum rank changes of -108 and +44 positions within the top 300 sires. The 5 th percentile rank change was -45 positions and the 95 th percentile rank change was +27 positions in the group of 1,500 sires when $\mathrm{NM} \$$ rank was compared with ANPV rank. Rank changes

Table 3. Pearson correlations of PTA traits with NM\$, ANPV, and AVOC indices from the top 1,500 marketed NM\$ Holstein sires in the December 2017 genetic evaluation ${ }^{1}$

\begin{tabular}{lrrr}
\hline & \multicolumn{3}{c}{ Index* $^{*}$ Trait $^{2}$} \\
\cline { 2 - 4 } & NM\$ & ANPV & AVOC \\
\hline Milk & 0.24 & 0.24 & 0.30 \\
Fat & 0.55 & 0.56 & 0.67 \\
PRO & 0.39 & 0.39 & 0.47 \\
PL & 0.52 & 0.50 & 0.34 \\
LIV & 0.31 & 0.29 & 0.17 \\
SCS & -0.05 & -0.06 & -0.14 \\
DPR & 0.24 & 0.23 & 0.13 \\
HCR & 0.14 & 0.14 & 0.09 \\
CCR & 0.30 & 0.30 & 0.19 \\
UDC & 0.11 & 0.12 & 0.11 \\
FLC & 0.07 & 0.07 & 0.05 \\
BWC & -0.24 & -0.24 & -0.24 \\
CA $\$$ & 0.25 & 0.25 & 0.24
\end{tabular}

${ }^{1} \mathrm{NM} \$=$ lifetime net merit dollars; ANPV $=$ annualized net present value; $\mathrm{AVOC}=$ annualized value with opportunity cost.

${ }^{2} \mathrm{PRO}=$ protein $; \mathrm{PL}=$ productive life $\mathrm{LIV}=$ livability $; \mathrm{DPR}=$ daughter pregnancy rate; $\mathrm{HCR}=$ heifer conception rate; $\mathrm{CCR}=\mathrm{cow}$ conception rate; UDC = udder composite; FLC = feet and legs composite; $\mathrm{BWC}=\mathrm{BW}$ composite; $\mathrm{CA} \$=$ calving ability.

*All correlations are significantly different from $0(P \leq 0.05)$. 
between $\mathrm{NM} \$$ and AVOC were larger than the rank changes between NM $\$$ and ANPV. The greatest changes between $\mathrm{NM} \$$ rank and AVOC rank were a decrease of 472 positions and an increase of 259 positions for the 1,500 sires (Figure 4). Maximum changes in the group of the top 300 sires were -343 and +93 positions. The 5 th percentile sire's rank change was -163 positions, whereas the 95th percentile sire's rank change was +131 positions.

Table 4 shows results from the linear regression equations for rank changes of NM $\$$ compared with ANPV and AVOC for 1,500 sires to discover the traits that most influenced rank changes. Coefficients of each trait explain the effect on the rank change from a single unit change of that trait. The regression model for rank change of NM\$ compared with ANPV had a coefficient of determination $\left(\mathrm{R}^{2}\right)$ of 0.549 . We found positive $(P<$ 0.05 ) coefficients for fat, protein, HCR, UDC, and PL and negative coefficients for milk, LIV, SCS, BWC, and $\mathrm{PL}^{2}$. The regression model for rank changes of $\mathrm{NM} \$$ compared with AVOC had an $\mathrm{R}^{2}$ of 0.850 and resulted in positive $(P<0.05)$ coefficients for fat, protein, DPR, $\mathrm{HCR}, \mathrm{UDC}, \mathrm{CA} \$$, and $\mathrm{PL}^{2}$ and negative coefficients for milk, SCS, BWC, and PL. Because greater rank changes were observed for AVOC than for ANPV compared with $\mathrm{NM} \$$, greater coefficients for the AVOC rank change regression model were expected and gener- ally observed. The coefficients for LIV, PL, and $\mathrm{PL}^{2}$ were in opposing directions in the ANPV and AVOC rank change regression models.

Figure 5 shows the association between $\mathrm{PL}$ and the rank changes for ANPV and AVOC compared with ranking for $\mathrm{NM} \$$ for the 1,500 sires. Sires with the highest PL generally ranked lower for ANPV and AVOC than for NM $\$$. If the rank changes agreed in direction, the AVOC rank change tended to be larger than the ANPV rank change. Moving to the middle of the PL distribution, more sires increased in rank than decreased in rank with ANPV, but the magnitude was less than that at the extreme PL values. Sires with the lowest PL generally ranked lower for ANPV than for $\mathrm{NM} \$$. In direct contrast, all sires with PL less than 6.6 mo resulted in a higher ranking for AVOC than NM $\$$.

\section{Residual Index Value Changes}

Using simple linear regression, ANPV was best estimated as $23.644+1.017 \times \mathrm{ANM} \$$. Residuals ordered by ANM $\$$ are plotted in Figure 6. Any sire above the $\$ 0$ line represents a higher actual ANPV than predicted based on his ANM\$. Within the top 300 sires ranked for $\mathrm{ANM} \$$ (greater than $\$ 313 \mathrm{ANM} \$$ ), the maximum increase was $\$ 4.49$, whereas the maximum decrease was $\$ 9.39$ from the predicted value.

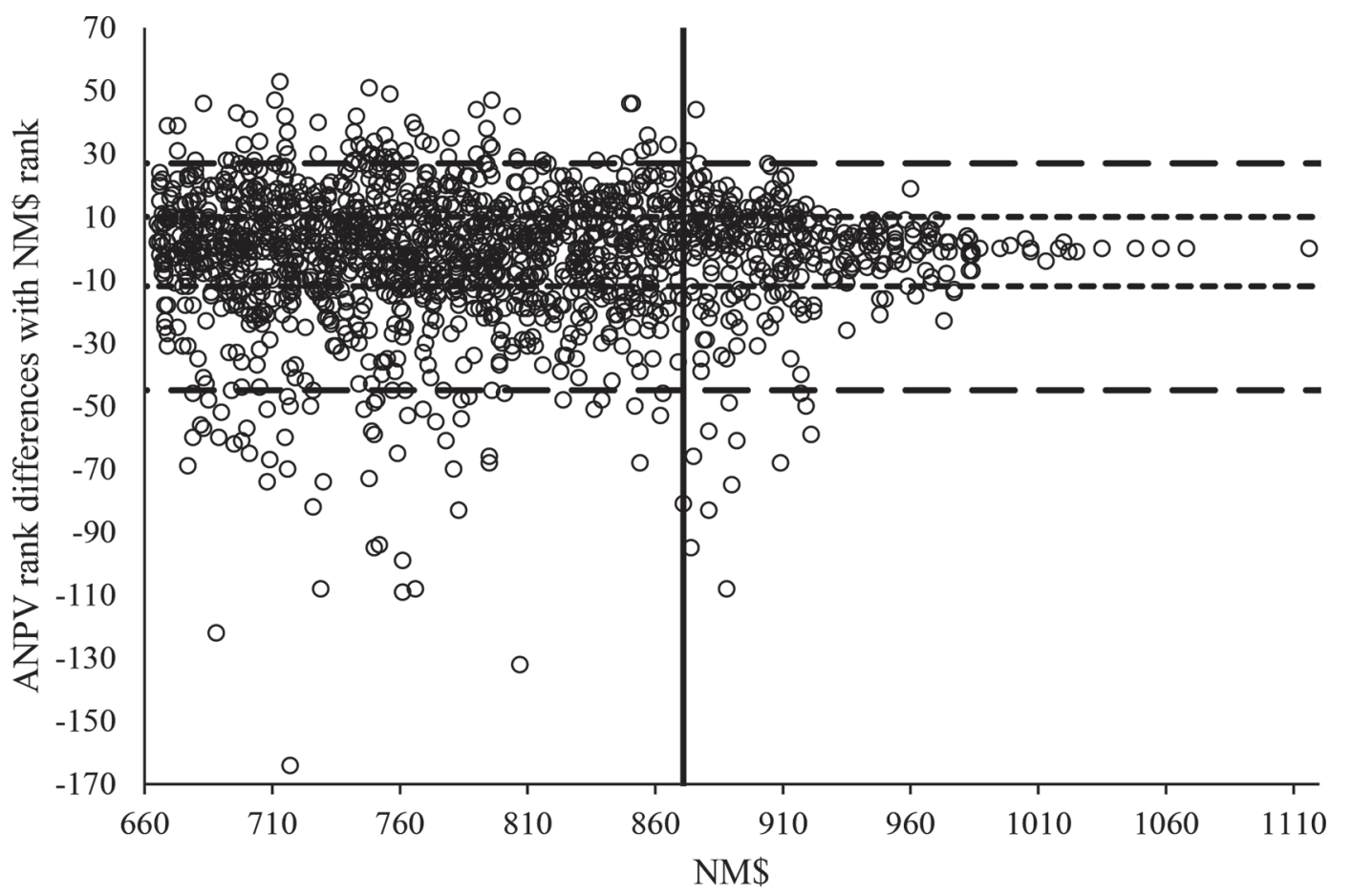

Figure 3. Lifetime net merit dollars (NM\$) rank differences from their annualized net present value (ANPV) rank for each of 1,500 Holstein sires ordered by $\mathrm{NM} \$$. The top $300 \mathrm{NM} \$$ sires can be found to the right of the vertical line $(\mathrm{NM} \$=\$ 871)$. Percentiles of rank change lines are drawn at $95 \%$ (long-dash line; +27), $75 \%$ (short-dash line; +10), 25\% (short-dash line; -12 ), and 5\% (long-dash line; -45 ). Positive values represent a better ranking for ANPV than NM\$. 


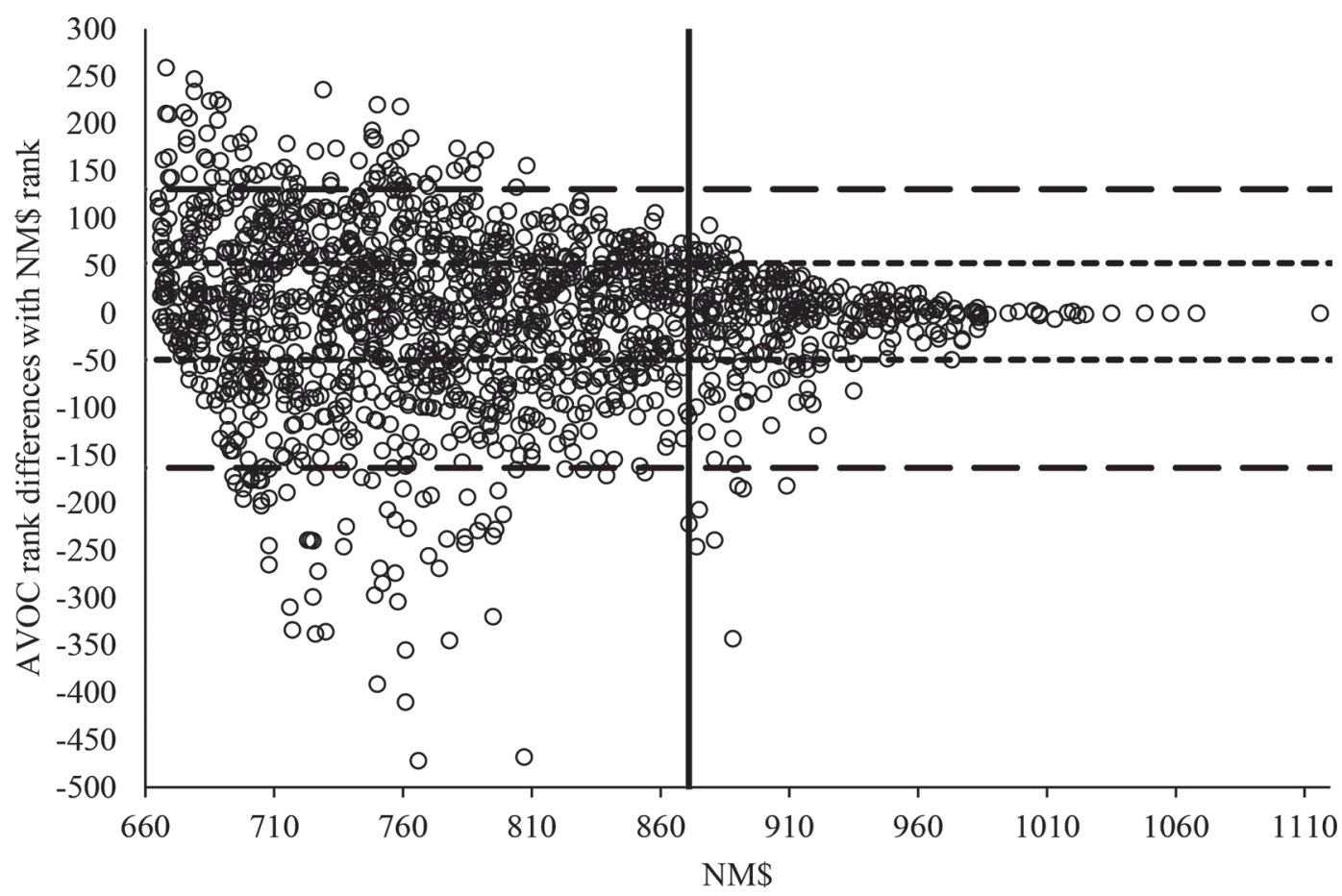

Figure 4. Lifetime net merit dollars $(\mathrm{NM} \$)$ rank difference from their annualized value with opportunity cost (AVOC) rank for each of 1,500 Holstein sires ordered by NM $\$$. The top $300 \mathrm{NM} \$$ sires can be found to the right of the vertical line (NM $\$=\$ 871)$. Percentile of rank change lines are drawn at 95\% (long-dash line; +131), 75\% (short-dash line; +53), 25\% (short-dash line; -49 ), and 5\% (long-dash line; -163). Positive values represent a better ranking for AVOC than NM\$.

The AVOC was best estimated as $95.144+0.717 \times$ ANM\$. Residuals of actual and predicted AVOC were greater than residuals for ANPV predicted by ANM $\$$. The correlation of the residuals was 0.423 . The AVOC residuals are shown in Figure 7, ordered by ANM $\$$. The largest residual value decrease by any sire was $\$ 25.43$, whereas the greatest value increase was $\$ 11.02$. The standard deviation of the AVOC residuals was $\$ 4.34$,

Table 4. Multivariable linear regression with the rank change between NM\$ and ANPV as the dependent variable and the PTA of 13 traits modeled as independent variables, except that $\mathrm{PL}^{2}$ was added to obtain randomly distributed residuals (left), and another multivariable linear regression with the rank change between $\mathrm{NM} \$$ and $\mathrm{AVOC}$ as the dependent variable and the same independent variables (right) ${ }^{1}$

\begin{tabular}{|c|c|c|c|c|c|c|c|}
\hline Trait $^{2}$ & Unit & \multicolumn{3}{|c|}{$\mathrm{NM} \$$ rank and ANPV rank change } & \multicolumn{3}{|c|}{$\mathrm{NM} \$$ rank and AVOC rank change } \\
\hline Intercept & & -237.663 & 13.370 & $<0.001$ & 322.215 & 31.623 & $<0.001$ \\
\hline Fat & Pounds & 0.204 & 0.029 & $<0.001$ & 1.838 & 0.068 & $<0.001$ \\
\hline PRO & Pounds & 0.255 & 0.066 & $<0.001$ & 2.075 & 0.157 & $<0.001$ \\
\hline PL & Months & 64.132 & 1.922 & $<0.001$ & -70.900 & 4.546 & $<0.001$ \\
\hline DPR & Percentage & 1.567 & 0.823 & 0.057 & 5.860 & 1.948 & 0.003 \\
\hline $\mathrm{HCR}$ & Percentage & 2.798 & 0.461 & $<0.001$ & 3.496 & 1.090 & 0.001 \\
\hline CCR & Percentage & 0.389 & 0.790 & 0.622 & 2.213 & 1.867 & 0.236 \\
\hline UDC & Composite & 5.697 & 0.813 & $<0.001$ & 21.253 & 1.922 & $<0.001$ \\
\hline FLC & Composite & -0.680 & 0.855 & 0.427 & 3.990 & 2.022 & 0.049 \\
\hline BWC & Composite & -1.611 & 0.609 & 0.008 & -11.834 & 1.440 & $<0.001$ \\
\hline $\mathrm{CA} \$$ & Dollars & 0.057 & 0.032 & 0.079 & 0.448 & 0.077 & $<0.001$ \\
\hline
\end{tabular}

${ }^{1} \mathrm{NM} \$=$ lifetime net merit dollars; ANPV = annualized net present value; AVOC = annualized value with opportunity cost.

${ }^{2} \mathrm{PRO}=$ protein $; \mathrm{PL}=$ productive life; $\mathrm{LIV}=$ livability $\mathrm{DPR}=$ daughter pregnancy rate; $\mathrm{HCR}=$ heifer conception rate; CCR $=$ cow conception

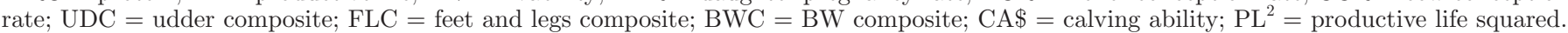


almost 3 times greater than the standard deviation of the ANPV residuals of $\$ 1.59$.

\section{Relative Trait Emphasis}

Regression equations with all PTA traits as explanatory variables and 1 of the 3 indices as a response variable $\left(\mathrm{R}^{2}>0.99\right)$ provided coefficients used for the relative emphasis from each PTA trait (Table 5). Trait coefficients for $\mathrm{ANM} \$$ were almost identical to the input economic weights from Table 1, as expected, and consequently had a very similar relative emphasis compared with NM\$ (VanRaden, 2017). Relative emphasis on PL, LIV, and FLC decreased by $0.4,0.5$, and 0.2 percentage points, respectively, for ANPV compared with ANM\$. Milk, fat, UDC, CCR, and HCR had slightly greater relative emphasis in ANPV than ANM $\$$.

The relative emphasis of PL in AVOC was $6.7 \%$ compared with $13.5 \%$ in $\mathrm{ANM} \$$. This was the largest decrease in relative emphasis of all traits. All other traits, except LIV and HCR, which remained unchanged, slightly increased in relative emphasis in AVOC compared with ANM \$, notably fat (1.8 percentage points) and protein (1.3 percentage points). The AVOC had greater relative emphasis for all traits, except $\mathrm{PL}, \mathrm{CCR}$, and milk, compared with ANPV. Other than for PL, no trait changed relative emphasis more than 2 percentage points between the 3 indices.

\section{Ranked Sire Similarity}

Figure 8 shows the percentage of the same sires when comparing the highest ranked sires for each index. All indices identified the same 5 highest sires $(100 \%$ similarity), but similarity was generally lower when fewer sires were compared. Minimum similarities were $83 \%$ (top 6 sires) for $\mathrm{NM} \$$ versus ANPV, $78 \%$ (top 37 sires) for NM\$ versus AVOC, and 85\% (top 41 sires) for ANPV versus AVOC.

\section{DISCUSSION}

We developed 2 genetic selection indices using financial investment methods and compared their values with the NM $\$$ values for 1,500 marketed Holstein sires that had a December 2017 genetic evaluation. Both ANPV and AVOC selection indices were highly correlated with $\mathrm{NM} \$$ on which the economic assumptions of our new indices were based. The new indices showed sufficient reranking of sires to warrant consideration for future use, however. Both new indices express the value of genetic merit differences of animals in terms of the value transmitted to the offspring, as does the $\mathrm{NM} \$$ index. Both new indices also do not include the additional profit that will be expressed in granddaughters and more remote descendants, again in agreement with the $\mathrm{NM} \$$ index. Estimated breeding values for the new

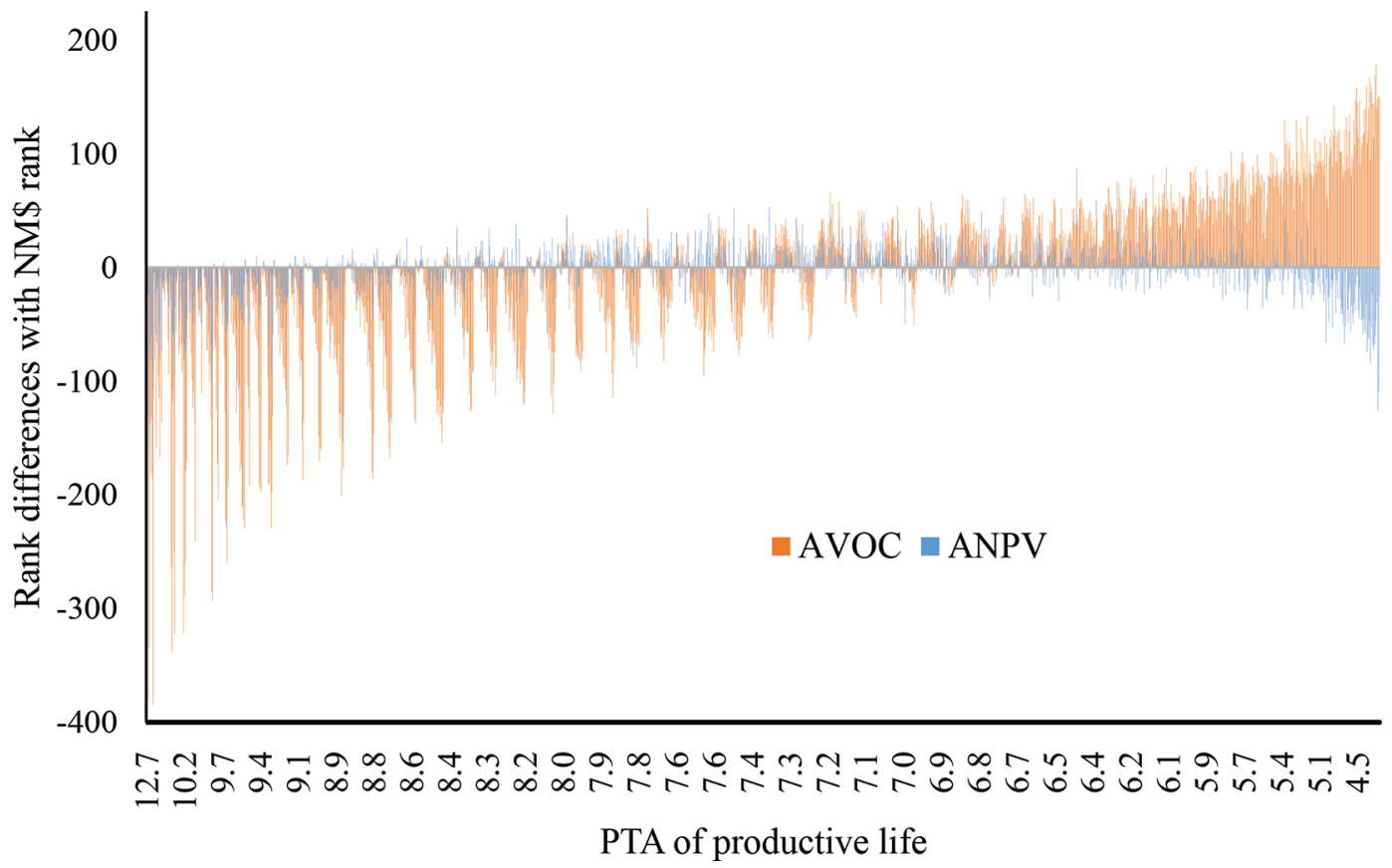

Figure 5. Differences between rank based on lifetime net merit dollars (NM\$) and rank based on annualized net present value (ANPV) in blue and annualized value with opportunity cost (AVOC) in orange, ordered by the PTA for productive life for 1,500 Holstein sires. When productive life was equal for sires, the second level of ordering was by descending NM\$. Positive values represent a higher ranking for ANPV or AVOC than for NM\$. 
indices can be calculated by multiplying the ANPV and AVOC by 2 .

The concepts of ANPV and AVOC can also be used to improve the prediction of the future value of females. For example, the Irish cow own worth index ranks females on expected profit for the remainder of their lifetime (Kelleher et al., 2015). This index blends both additive and nonadditive genetic merit, permanent environmental effects, and the current state of the animal such as DIM and pregnancy status. Indices such as the cow own worth index can be used for culling decisions as well as to inform purchase and sale decisions and may guide optimal replacement rates. The concept of such an index can be extended to heifers. Culling and insemination decisions for heifers and cows could further be optimized through application of sequential decision-making techniques such as dynamic programming (e.g., Mourits et al., 2000; Nielsen et al., 2010).

\section{Design of ANPV and AVOC Selection Indices}

The first major component of both new selection indices proposed in this study is that animals get credit for traits that have value each lactation for the dura- tion of their time in the herd and not the standard 2.78 lactations. Longer PL favors animals with high values of traits that repeat every lactation, such as high fat and protein, but penalizes animals with low values for traits that repeat every lactation. We made choices regarding adjustment of the PL, breed base net revenue, and discount rate that apply to both ANPV and AVOC.

The PL of the 1,500 sires ranged from +1.9 to +12.7 mo. When a PL of 0 mo equals 2.78 lactations $(27.8$ mo of production), this implies that the expected number of lactations ranged from 2.97 to 4.05. Despite increases in the PTA of PL, phenotypic longevity as reported by CDCB (2018) has not changed accordingly but rather has remained approximately constant in the last $20 \mathrm{yr}$. Therefore, cow cull rates do not proportionally decrease when PL increases. Assuming the continuation of the approximately $35 \%$ cull rate over the past $20 \mathrm{yr}$, absolute expression of differences in PL is restricted because qualifications to earn a place in the herd increase over time. Full expression of the average PL of sires in our data set would result in the annual herd cull rate decreasing from $35 \%$ to $28 \%$ in 1 generation. We believed this to be unrealistic. Estimation of the expected num-

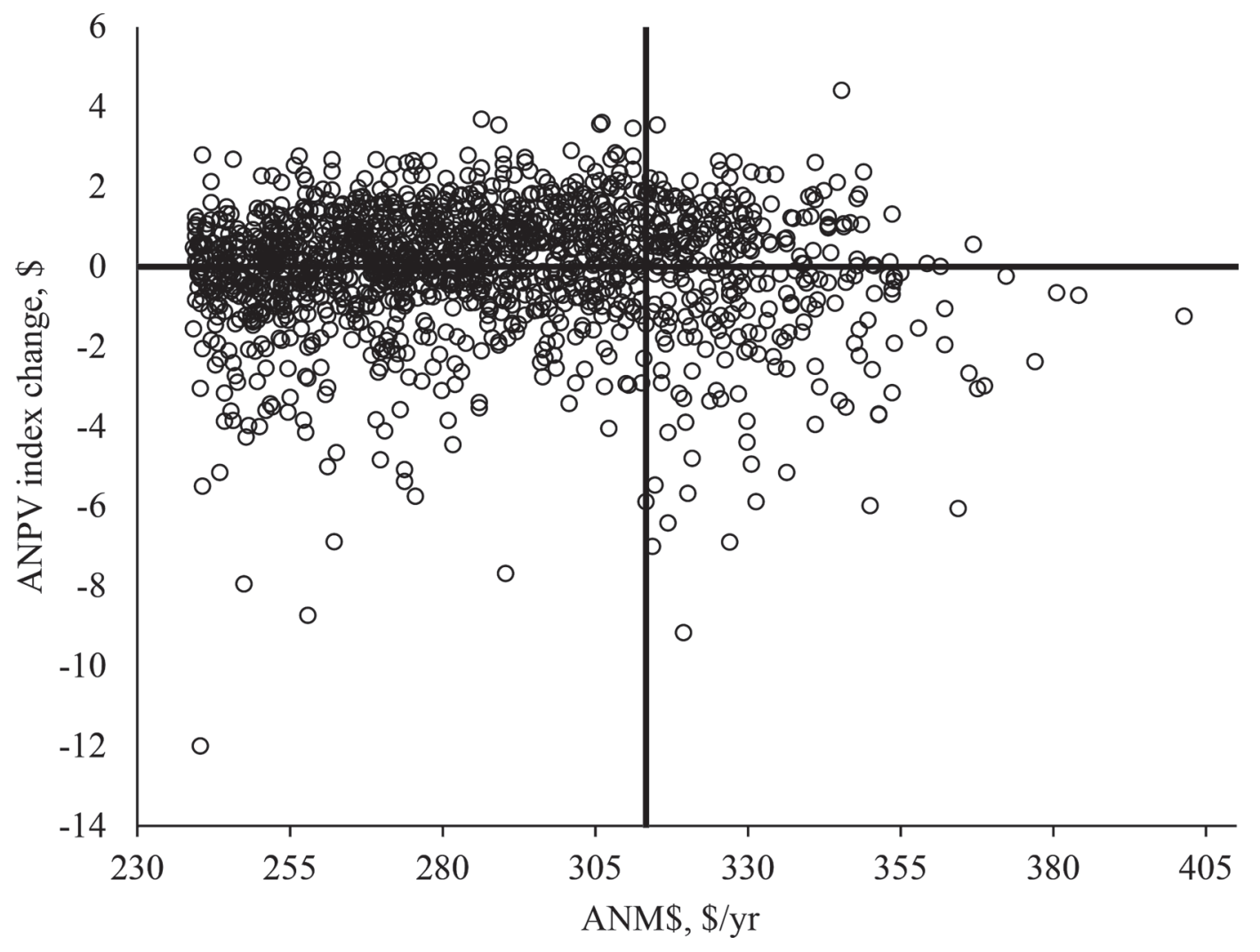

Figure 6. Annualized net present value (ANPV) index changes as residuals from the univariate regression equation ANPV $=23.644+1.017$ $\times \mathrm{ANM} \$$, by ordered $\mathrm{ANM} \$$ for 1,500 Holstein sires. $\mathrm{ANM} \$=$ annualized net merit dollars. The top $300 \mathrm{NM} \$$ sires can be found to the right of the vertical line at $\$ 313$ ANM $\$$. 
Table 5. Three multivariable linear regression equations with ANM $\$$, ANPV, and AVOC as the dependent variables and PTA of 13 traits as independent variables ${ }^{1}$

\begin{tabular}{|c|c|c|c|c|c|c|c|c|c|c|}
\hline \multirow[b]{2}{*}{ Trait $^{2}$} & \multirow[b]{2}{*}{ Unit } & \multicolumn{3}{|c|}{ ANM\$ } & \multicolumn{3}{|c|}{ ANPV } & \multicolumn{3}{|c|}{ AVOC } \\
\hline & & Coefficient $^{3}$ & SE & $\begin{array}{c}\text { Relative } \\
\text { emphasis, \% }\end{array}$ & Coefficient & SE & $\begin{array}{c}\text { Relative } \\
\text { emphasis, \% }\end{array}$ & Coefficient & $\mathrm{SE}$ & $\begin{array}{c}\text { Relative } \\
\text { emphasis, \% }\end{array}$ \\
\hline Intercept & & 126.163 & 0.581 & & 151.343 & 0.983 & & 197.143 & 0.802 & \\
\hline Milk & Pounds & -0.001 & 0.000 & 0.7 & -0.002 & 0.000 & 0.8 & -0.001 & 0.000 & 0.8 \\
\hline Fat & Pounds & 1.280 & 0.001 & 23.6 & 1.315 & 0.002 & 23.7 & 1.027 & 0.002 & 25.4 \\
\hline PRO & Pounds & 1.370 & 0.003 & 18.2 & 1.406 & 0.006 & 18.2 & 1.098 & 0.005 & 19.5 \\
\hline SCS & $\log$ & -42.135 & 0.201 & 6.5 & -43.122 & 0.340 & 6.5 & -34.149 & 0.277 & 7.1 \\
\hline DPR & Percentage & 3.984 & 0.041 & 6.8 & 4.104 & 0.070 & 6.8 & 3.246 & 0.057 & 7.4 \\
\hline $\mathrm{HCR}$ & Percentage & 0.747 & 0.023 & 1.3 & 0.880 & 0.039 & 1.5 & 0.767 & 0.032 & 1.8 \\
\hline CCR & Percentage & 0.787 & 0.039 & 1.6 & 0.859 & 0.067 & 1.7 & 0.591 & 0.054 & 1.6 \\
\hline UDC & Composite & 10.876 & 0.041 & 7.2 & 11.601 & 0.069 & 7.5 & 8.995 & 0.056 & 8.0 \\
\hline FLC & Composite & 3.661 & 0.043 & 2.8 & 3.558 & 0.072 & 2.6 & 2.832 & 0.059 & 2.9 \\
\hline BWC & Composite & -7.206 & 0.030 & 5.8 & -7.366 & 0.051 & 5.8 & -5.818 & 0.042 & 6.3 \\
\hline
\end{tabular}

${ }^{1}$ The resulting coefficients are the approximate marginal dollars per PTA unit. The relative emphasis is the absolute value of the coefficient multiplied by the standard deviation of the true transmitting ability for that trait and then divided by the sum of the absolute value of all coefficients multiplied by the standard deviation values, where the total sums for ANM\$, ANPV, and AVOC are 136, 139, and 101, respectively. ANM $\$=$ annualized net merit dollars; ANPV = annualized net present value; AVOC = annualized value with opportunity cost.

${ }^{2} \mathrm{PRO}=$ protein $\mathrm{PL}=$ productive life; $\mathrm{LIV}=$ livability; $\mathrm{DPR}=$ daughter pregnancy rate; $\mathrm{HCR}=$ heifer conception rate; CCR = cow conception rate; $\mathrm{UDC}=$ udder composite; $\mathrm{FLC}=$ feet and legs composite; $\mathrm{BWC}=\mathrm{BW}$ composite; $\mathrm{CA} \$=$ calving ability.

${ }^{3}$ All coefficients had $P$-values $<0.001$.

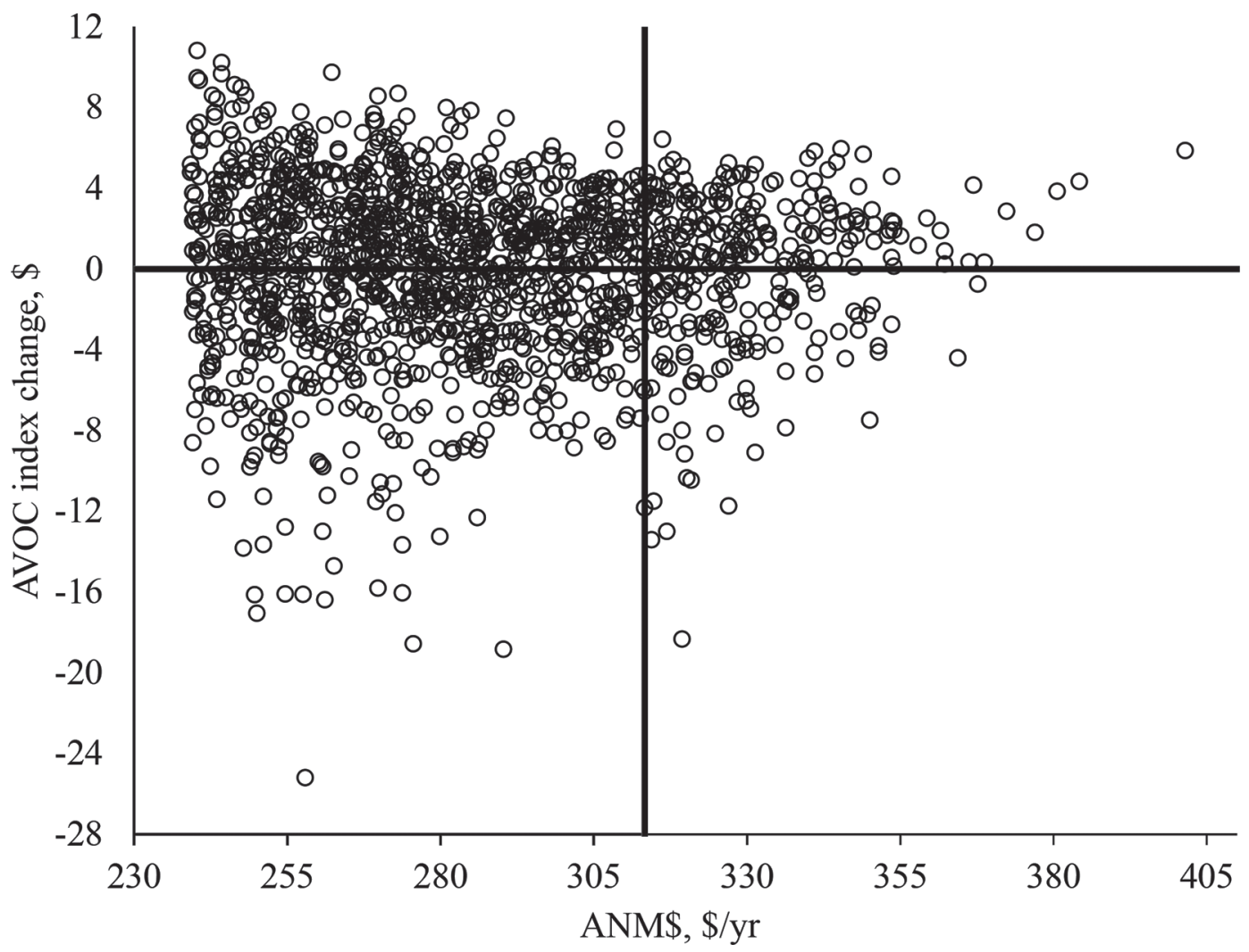

Figure 7. Annualized value with opportunity cost (AVOC) index changes as residuals from the univariate regression equation AVOC $=$ $95.144+0.717 \times \mathrm{ANM} \$$, by ordered $\mathrm{ANM} \$$ for 1,500 Holstein sires. ANM $\$=$ annualized net merit dollars. The top $300 \mathrm{NM} \$$ sires can be found to the right of the vertical line at $\$ 313 \mathrm{ANM} \$$. 
ber of lactations from each sire's PL required an adjustment of the PL to maintain consistent annual cow cull rates. We assumed that the differences in PL between the sires remained. Therefore, the adjustment included subtraction of 7.4 mo from each sire's PL. After adjusting the PL in our analysis, the relative difference in expected lifetimes between sires remained the same, so investment return comparisons between sires continued to capture financial differences. If the expected lactations were not adjusted, Pearson correlations between $\mathrm{NM} \$$ and the new indices were reduced to 0.959 with ANPV and 0.907 with AVOC.

We calculated the net revenue of traits that repeat every lactation as the PTA of the trait times the expected number of lactations. Production of cows increases until approximately the fifth parity when the cow is mature (Schmidt et al., 1988). Sires with short PL therefore have daughters that are on average more juvenile and not able to produce mature quantities of milk and components. The PTA for milk, fat, and protein are corrected to production in 36-mo-old, secondparity cows in the national genetic evaluation system. In addition, part of the increase in production from greater maturity is nullified by the increased risk of death and disease in greater lactations (Shook, 2006). Therefore, we did not adjust the PTA for these production traits to account for differences in lifetime in the ANPV and AVOC.
The PTA of PL is dependent on credits generated from a cow's length of time in the herd, ability to return to another lactation quickly, and increased production from the effect of maturity (VanRaden et al., 2006). The PTA of PL is therefore not exactly equivalent to differences in the length of time between first calving and culling. This discrepancy has minor effects on the discount factors used in our study, but we believe that the total effect on the new indices is negligible.

We added a constant net revenue (base of $\$ 343.52$ in this study) to each lactation to include a reasonable income that is independent of the PTA and economic weights of the lactation traits. Adding this constant did not rerank sires and had no effect on the results. Without this constant, the sum of the net revenue from all lactation traits would be low on average, and the ANPV and AVOC would often be negative due to greater entry cost than exit revenue. The Pearson and Spearman rank correlations between ANPV and NM $\$$ are independent of the choice of the breed base because in the ANPV method the breed base has a scalar effect. Omission of a breed base amount reduced both the Pearson and Spearman rank correlations of $\mathrm{NM} \$$ and AVOC by 0.007 . These minor reductions in correlations are due to discounting effects.

The relative emphasis of each trait illustrates the relationship, or economic weighting, of the trait to the overall index. The relative emphasis of the traits in

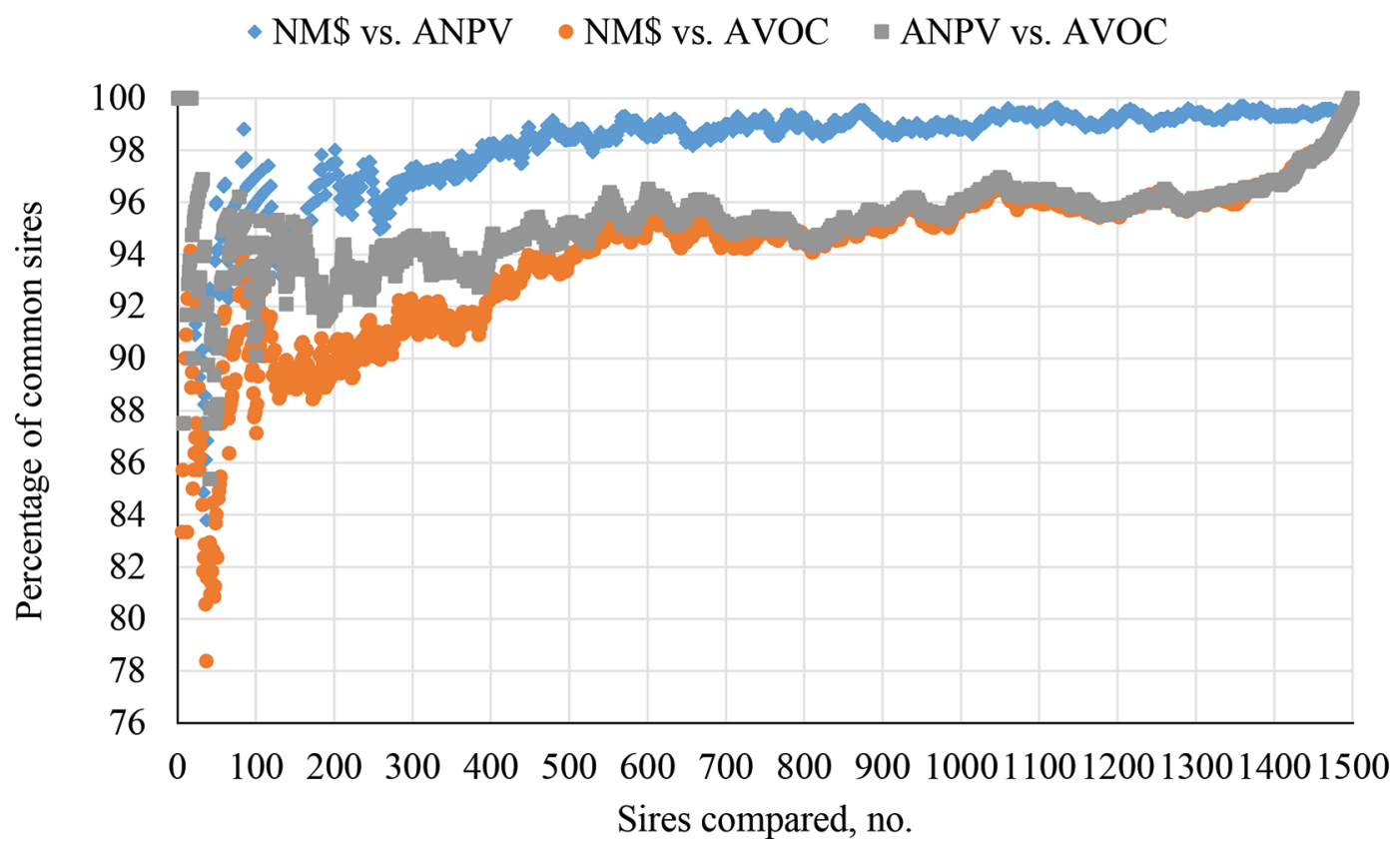

Figure 8. The percentage of sires in common between 2 indices for the highest ranking sires by each index. NM $\$=$ lifetime net merit dollars; $\mathrm{ANPV}=$ annualized net present value; $\mathrm{AVOC}=$ annualized value with opportunity cost. 
the ANPV was very similar to that for $\mathrm{ANM} \$$, but the relative emphasis of traits for AVOC was different. The reduction in relative emphasis on PL in AVOC compared with in ANM\$ was a direct consequence of the opportunity cost. Because long lifetimes have less value when considering the opportunity cost, the relative emphasis of other traits increased.

Varying the annual discount rates between $0 \%$ and $10 \%$ changed the Pearson correlation between ANPV, AVOC, and NM\$ less than 0.01. Although the Pearson correlation of ANPV and NM\$ was high, the effect of discounting can be observed through the relative emphasis of traits expressed only once, such as HCR and LIV in Table 5. The direction of the discounting effect depended on the time of expression and represents an over- or undervaluing of traits that vary in their timing of expression compared with ANM\$. Heifer conception rate was expressed at first calving and had an increase in relative emphasis for the ANPV index of $0.2 \%$ compared with ANM\$. Conversely, the relative emphasis of LIV decreased by $0.5 \%$ for ANPV compared with ANM\$.

Some discounting is applied to the values of PL and BWC in the NM\$ index but not to the lactation traits. Discounting methods have also been applied in other economic selection indices - for example, in Australia and Ireland. Both implement a discounted genetic value for traits of direct calving, calf carcass, and cull cows to account for the delay in expression and timing of cash flows (Berry et al., 2006; Byrne et al., 2016). Increased net revenue from increased calf carcass weight is realized more quickly and therefore more valuable than the same increased net revenue from increased cow carcass weights. Although our study discounted the cash flows in the middle of each lactation for simplicity, a more detailed discount method could be applied, such as on a daily basis (Smith et al., 1993). Daily discounting of cash flows from genetic expression could be applied to differences in production traits currently in the index that vary across the lactation (Rogers et al., 1988) as well as traits not included in our indices that vary throughout the lactation, such as lactation persistency, transition health events (VanRaden et al., 2018), and feed efficiency measures. Including discounting in a selection index as proposed in this study makes the index no longer a simple weighted average of the published PTA for the various traits, however. This loss of simplicity might hamper the adoption of such new indices.

The second major component of the AVOC index is the inclusion of the opportunity cost of delayed replacement. By keeping a current animal in the herd, one denies a replacement animal in the herd, and this opportunity cost needs to be included in an investment analysis (Perrin, 1972; Weigel et al., 1995). We made choices regarding the genetic level of the replacement animal and the planning horizon.

The first choice we made was the start level of the genetic merit of the replacement animal, which we assumed to be $\$ 342$ (average value of the top 100 sires ranked for ANPV). In practice, this choice would depend on the sire choice of the dairy farmer. Dairy farmers select sires based on semen price and availability, relationship of potential sires to females in the herd, risk attitude including importance of reliability of PTA (Tozer and Stokes, 2002), and their relationship with the semen salesperson. Our analysis showed that the choice of different genetic start levels for replacement animals had a minor effect on AVOC, but these differences are not negligible.

The scenario using only the highest net genetic value per year as the starting value for replacement sires $(\$ 390)$ rewards sires with a shorter PL due to the replacement sire's high value. Dairy farmers cannot choose the top sire as the only option for multiple reasons, such as price, availability, and inbreeding considerations. Conversely, if the average of all sires was used as the starting value for replacement sires $(\$ 287)$, the correlation between AVOC and NM $\$$ increased by 0.013 compared with the base scenario, where the average of the top 100 sires was used (\$342). In this scenario, high-ranking sires would be replaced by inferior replacement sires, which incentivizes sires with long PL. The best starting level of genetic trend for replacement sires is a topic for further investigation.

In addition, the length of time for which the net revenue from the replacement sires is included is relevant. The second choice we made was to set this time period to the longest expected lifetime in the data set (3.307 lactations) minus the expected lifetime of the sire to be evaluated. This choice is arbitrary. Hence, the sire with the longest expected lifetime and a PL of $+12.7 \mathrm{mo}$ had no opportunity cost. This longest lifetime might change with every genetic evaluation and depends on the sires that are compared. Longer periods would not change the absolute differences in NPV between current sires but would make their AVOC more similar. When we extended the planning horizon to $4 \mathrm{yr}$ (48 mo), the Pearson correlation increased only by $<0.001$ between AVOC and NM\$.

Opportunity cost has largely eluded consideration in economic genetic selection indices because it is an unrecognized loss if profitable animals are kept in the herd and difficult to capture. Cassell et al. (1993) found a correlation of 0.95 between 2 measures of a phenotypic profit function when one considered opportunity cost. Later research by Cassell et al. (2002) realized the importance of the genetic trend for replacements when estimating the opportunity cost for profit functions and 
found that the mean profit function with opportunity cost resulted in negative values because of the increasing superiority of replacement animals. We decided on a constant rate of genetic progress into the future for estimating opportunity cost. Given the increasing rate of genetic improvement as a result of genomic testing (García-Ruiz et al., 2016), the effect of opportunity cost may further decrease the relative emphasis of PL compared with that estimated in this study.

New traits that are or will be incorporated into the $\mathrm{NM} \$$ index can easily be implemented into the proposed indices, depending on their expression per lactation or per lifetime. For example, the recent incorporation of 6 health traits (VanRaden et al., 2018) is at a lactation basis, whereas the proposed incorporation of age at first calving is expressed per lifetime.

The NM\$, ANPV, and AVOC indices all express profit differences between animals per unit of time. We chose to express both new selection indices on an annualized basis (hence ANPV and AVOC), but this annual planning horizon is arbitrary. Before 2000, $\mathrm{NM} \$$ measured the annualized profit by dividing the PL value by 2.78 lactations and adding that value to a milk-fat-protein dollars index, which had measured profit per lactation since 1977 (VanRaden, 2000). The transition to a lifetime value was made to convince dairy producers of the larger real lifetime value differences between sires than an annual number expressed. One alternative option is therefore to multiply both ANPV and AVOC by 2.78 to show larger differences that appear to better show approximate lifetime value differences. However, such values would be standardized lifetime values rather than real lifetime values and would perhaps complicate interpretation. Alternatively, both ANPV and AVOC could be multiplied by the longest longevity in the data set (3.307 lactations, or $39.68 \mathrm{mo}$ ), but this value would change with every genetic evaluation. Choice of the time frame would not change rankings and relative differences between animals.

The ANPV and AVOC selection indices are constructed based on standard financial investment methods and logic. Ideally, economic selection indices including NM\$ are validated through their association with real profitability of (offspring of) animals. Perhaps an index that predicts real profit differences should be preferred, although this assumes that dairy farmers make rational, risk-free, unbiased selection decisions. This is likely not the case. In an older study, Cassell et al. (2002) found that NM $\$$ was a robust and useful index that accurately identified sires whose daughters generated highest lifetime economic merit. In Ireland, the economic breeding index predicted change in herd profitability per unit change that was within expectation (Ramsbottom et al., 2012). In Australia, a case study showed that cows with high genetic merit contributed more to farm profit each year without compromising their PL or incurring higher breeding or mastitis treatment costs (Newton et al., 2017). These studies did not compare differently constructed economic indices. Here lies an opportunity for further research.

\section{IIlustrative Example}

We illustrate the ANPV and AVOC index values for 3 sires. Achilles is a sire with a PL of $+11.5 \mathrm{mo}$ and $+19 \mathrm{lb}$. of fat. He is ranked 1,166th for $\mathrm{NM} \$(\$ 717)$ and ANM\$ (\$258). His PL indicates that his daughters will remain in the herd for a long time, but they will be generating low net revenues from lactation traits. When the opportunity cost of delaying entry of replacement sires is included, which are vastly more profitable per lactation, he becomes the 1,500 th ranked sire in our data set. His daughters have an AVOC of $\$ 254$ and the residual AVOC index value is $\$ 25.43$ lower compared with what is expected based on their ANM $\$$. The residual ANPV index value is $\$ 8.73$ lower than what is expected based on their ANM $\$$. This means that ANM\$ overpredicts the ANPV and AVOC by these values on an annual basis. A sire with a similar high number of expected lactations is High Noon, with a PTA of PL of +11.1 mo, but he has drastically better lactation traits-for example, $+71 \mathrm{lb}$. of fat. His residual ANPV and AVOC index changes were $-\$ 6.05$ and $-\$ 4.40$, respectively. Here, the AVOC diverged from ANM\$ less than ANPV from $\mathrm{ANM} \$$, which is the opposite of Achilles because High Noon remained more competitive compared with replacement sires. High Noon's rank change for AVOC was -6 compared with Achilles's rank change of -334 . Therefore, not all sires with a high PL were penalized equally in the AVOC method.

In contrast, a sire with low PL of +2.7 mo resulting in a short expected number of lactations is Peterpan. He has a similar NM\$ (\$729), ANM\$ (\$262), and ranking $(1,102$ th $)$ as Achilles. Peterpan's revenue per year is vastly greater $(+\$ 114)$ than Achilles's revenue as a result of $+112 \mathrm{lb}$. of fat. He decreased in rank to 1,211 on the ANPV index, but on the AVOC index he improved in rank to 869. The $\mathrm{ANM} \$$ overpredicts the ANPV by $-\$ 6.89$ because the effects of fewer but more profitable lactations were not accounted for in the ANM $\$$. However, the ANM $\$$ underpredicts the AVOC by $\$ 9.74$. The contrasting directions of prediction from ANM $\$$ demonstrate that including the opportunity cost from superior replacements can change the effect of PL. Peterpan is expected to generate $\$ 292 / \mathrm{yr}$ based on AVOC. When Peterpan is compared with Achilles, a $\$ 4 / \mathrm{yr}$ difference in $\mathrm{ANM} \$$ has increased to a $\$ 38 / \mathrm{yr}$ difference in AVOC. 


\section{CONCLUSIONS}

Financial investment analysis was used to develop 2 new economic genetic selection indices with the same inputs as the linear approximation of the $\mathrm{NM} \$$ selection index. The ANPV method included improved accounting for differences in PL between sires assuming identical replacement, and the AVOC method also included the opportunity cost of delayed replacement with not-identical replacements. The AVOC approach for selecting animals would maximize net revenue across time. Faster progress from genomic selection increases the genetic merit of future replacements and decreases the value of PL. High correlations between the NM\$ and the ANPV method were found, but rankings were significantly different for some sires. Including the opportunity cost of increasingly superior replacements decreased the correlations of AVOC and NM\$. Rank changes were meaningful enough that both indices warrant consideration for use in practice.

\section{REFERENCES}

Berry, D. P., F. E. Madalena, A. R. Cromie, and P. R. Amer. 2006. Cumulative discounted expressions of dairy and beef traits in cattle production systems. Livest. Sci. 99:159-174.

Brown, C., and K. Davis. 1998. Options in mutually exclusive projects of unequal lives. Q. Rev. Econ. Finance 38:569-577. https://doi .org/10.1016/S1062-9769(99)80090-8.

Byrne, T. J., B. F. S. Santos, P. R. Amer, D. Martin-Collado, J. E. Pryce, and M. Axford. 2016. New breeding objectives and selection indices for the Australian dairy industry. J. Dairy Sci. 99:81468167.

Cassell, B. G., S. M. Jobst, M. L. McGilliard, and R. E. Pearson. 2002. Evaluating sire selection practices using lifetime net income functions. J. Dairy Sci. 85:3492-3502.

Cassell, B. G., B. B. Smith, and R. E. Pearson. 1993. Influence of herdlife opportunity and characteristics of cows and herds on different net income functions. J. Dairy Sci. 76:1182-1190.

CDCB (Council on Dairy Cattle Breeding). 2017. Official sire evaluation files. December 2017. Accessed Dec. 15, 2017. https://queries uscdcb.com/CAevalfiles.htm.

CDCB (Council on Dairy Cattle Breeding). 2018. Genetic and phenotypic trend. Accessed Nov. 20, 2018. https://queries.uscdcb.com/ eval/summary/trend.cfm.

Cole, J. B., and R. M. VanRaden. 2018. Symposium review: Possibilities in an age of genomics: The future of selection indices. J. Dairy Sci. 101:3686-3701.

De Vries, A. 2017. Economic trade-offs between genetic improvement and longevity in dairy cattle. J. Dairy Sci. 100:4184-4192.

García-Ruiz, A., J. B. Cole, P. M. VanRaden, G. R. Wiggans, J. F. Ruiz-Lopez, and C. P. Van Tassell. 2016. Changes in genetic selection differentials and generation intervals in US Holstein dairy cattle as a result of genomic selection. Proc. Natl. Acad. Sci. USA 113:E3995-E4004.

Groenendaal, H., D. T. Galligan, and H. A. Mulder. 2004. An economic spreadsheet model to determine optimal breeding and replacement decisions for dairy cattle. J. Dairy Sci. 87:2146-2157.

Higgins, R. C. 2001. Discounted cash flow techniques. Pages 263-267 in Analysis for Financial Management. 6th ed. Irwin/McGrawHill, New York, NY.

Kelleher, M. M., P. R. Amer, L. Shalloo, R. D. Evans, T. J. Byrne, F. Buckley, and D. P. Berry. 2015. Development of an index to rank dairy females on expected lifetime profit. J. Dairy Sci. 98:4225-4239.

Mourits, M. C., D. T. Galligan, A. A. Dijkhuizen, and R. B. Huirne. 2000. Optimization of dairy heifer management decisions based on production conditions of Pennsylvania. J. Dairy Sci. 83:1989-1997.

Newton, J. E., M. E. Goddard, H. N. Phuong, M. A. Axford, C. K. M. Ho, N. C. Nelson, C. F. Waterman, B. J. Hayes, and J. E. Pryce. 2017. High genetic merit dairy cows contribute more to farm profit: Case studies of 3 Australian dairy herds. Proc. Assoc. Advancement Anim. Breed. Genet. 22:19-22.

Nielsen, L. R., E. Jørgensen, A. R. Kristensen, and S. Ostergaard. 2010. Optimal replacement policies for dairy cows based on daily yield measurements. J. Dairy Sci. 93:75-92.

Perrin, R. K. 1972. Asset replacement principles. Am. J. Agric. Econ. 54:60-67.

Ramsbottom, G., A. R. Cromie, B. Horan, and D. P. Berry. 2012. Relationship between dairy cow genetic merit and profit on commercial spring calving dairy farms. Animal 6:1031-1039.

Rogers, G. W., J. A. M. van Arendonk, and B. T. McDaniel. 1988. Influence of production and prices on optimum culling rates and annualized net revenue. J. Dairy Sci. 71:3453-3462.

Schmidt, G. H., L. D. Van Vleck, and M. F. Hutjens. 1988. Principles of Dairy Science. 2nd ed. Prentice Hall, Englewood Cliffs, NJ.

Shook, G. E. 2006. Major advances in determining appropriate selection goals. J. Dairy Sci. 89:1349-1361.

Smith, R. M., J. F. Taylor, J. P. Walter, M. A. Tomaszewski, C. G. Woelfel, and D. J. Leatham. 1993. Seasonal effects on income over feed and replacement costs. J. Dairy Sci. 76:1678-1692.

Tozer, P. R., and J. R. Stokes. 2002. Producer breeding objectives and optimal sire selection. J. Dairy Sci. 85:3518-3525.

Van Arendonk, J. A. M. 1991. Use of profit equations to determine relative economic value of dairy cattle herd life and production from field data. J. Dairy Sci. 74:1101-1107.

VanRaden, P. M. 2000. Net merit as a measure of lifetime profit-2000 version. USDA-AIPL Research Report NM\$1 (11-00). Accessed Nov. 20, 2018. https://aipl.arsusda.gov/reference/nmcalc-2000 .htm.

VanRaden, P. M. 2017. Net merit as a measure of lifetime profit: 2017 revision. AIP Research Report NM\$6 (2-17). Accessed Nov. 20, 2018. https://aipl.arsusda.gov/reference/nmcalc-2017.htm.

VanRaden, P. M., J. B. Cole, and K. L. Parker-Gaddis. 2018. Net merit as a measure of lifetime profit: 2018 revision. AIP Research Report NM\$7 (5-18). Accessed Nov. 20, 2018. https://aipl.arsusda .gov/reference/nmcalc-2018.htm.

VanRaden, P. M., M. Dematwewa, R. Pearson, and M. Tooker. 2006. Changes to evaluation system (August 2006). Accessed Nov. 20, 2018. https://aipl.arsusda.gov/reference/changes/eval0608.html.

Weigel, D. J., B. G. Cassell, and R. E. Pearson. 1995. Adjustment of a net income function for opportunity cost of postponed replacement on a lactation basis. J. Dairy Sci. 78:648-654. 